\title{
Isolation of a novel strain of Candida shehatae for ethanol production at elevated temperature
}

\author{
Ayumi Tanimura ${ }^{1 \dagger}$, Toshihide Nakamura ${ }^{2 \dagger}$, Itsuki Watanabe ${ }^{2}$, Jun Ogawa ${ }^{3}$ and Jun Shima ${ }^{\text {* }}$
}

\begin{abstract}
Considering the cost-effectiveness of bioethanol production, there is a need for a yeast strain which can convert glucose and xylose into ethanol at elevated temperatures. We succeeded in isolating a yeast strain, designated strain ATY839, which was capable of ethanolic fermentation at temperatures above those previously reported for yeasts able to ferment both glucose and xylose. Strain ATY839 was capable of producing a substantial amount of ethanol at up to $37^{\circ} \mathrm{C}$ from $2 \%$ glucose or $2 \%$ xylose. The results of a phylogenetic analysis suggest that strain ATY839 belongs to Candida shehatae. In additional, ethanol production from rice straw by strain ATY839 was examined. Compared with the control strains (Saccharomyces cerevisiae NBRC 0224, Scheffersomyces stipitis NBRC 10063, and C. shehatae ATCC 22984), strain ATY839 produced more ethanol in SSF even at $37^{\circ} \mathrm{C}$. The theoretical maximum yield of strain ATY839 was $71.6 \%$ at $24 \mathrm{~h}$. Thus, strain ATY839 is considered to be the most tolerant to high temperature of the $C$. shehatae strains.
\end{abstract}

Keywords: Candida shehatae, Bioethanol production, High-temperature fermentation, Rice straw, SSF

\section{Introduction}

The efficient use of natural resources for bioethanol production has been explored by several research groups (Balat 2011; Binod et al. 2010; Sarkar et al. 2012). At present, most bioethanol is produced from food crops such as corn grain or sugar cane (Kim \& Dale 2004; Sanchez \& Cardona 2008); however, the use of starch and sugar for the production of bioethanol competes with crops for food supplies. As an alternative, a lignocellulosic biomass product such as corn stover, corn fiber, rice straw, bagasse or wheat straw could become indispensable resources for bioethanol production. In Japan, for example, approximately $75 \%$ of rice straw is not used effectively which could therefore be an abundant feedstock for bioethanol production.

Plant cell walls are composed of three main components: cellulose, hemicellulose, and lignin. To achieve high-efficiency ethanol production, it is desirable to use both the glucose and xylose contained in the cellulose and hemicellulose (Kuhad et al. 2011). However, few types of yeast such as Scheffersomyces stipitis (formerly

\footnotetext{
*Correspondence: shimaj@kais.kyoto-u.ac.jp

${ }^{\dagger}$ Equal contributors

'Research Division of Microbial Sciences, Kyoto University, Kitashirakawa

Oiwake-Cho, Sakyo-ku, Kyoto 606-8502, Japan

Full list of author information is available at the end of the article
}

known as Pichia stipitis), Candida shehatae, and Spathaspora passalidarum have been found capable of xylose fermentation (Hou 2012; Jeffries et al. 2007; Prior et al. 1989); simultaneous utilization of these sugars has been problematic. The most generally used yeast strain in current bioethanol production processes, Saccharomyces cerevisiae, can ferment glucose derived from cellulose to ethanol; however, it normally lacks the ability to produce ethanol by fermenting the xylose present in hemicellulose (Jeffries \& Jin 2004; Kuhad et al. 2011). Thus, there has been extensive exploration to develop yeasts which can produce bioethanol from xylose with a high yield. Toward this end, researchers have tried to genetically improve $S$. cerevisiae and to co-culture two strains. The genetic improvement strategies are founded on the metabolism of wild xylose fermentable yeast, such as S. stipitis. For example, xylose reductase and xylitol dehydrogenase genes from S. stipitis have been introduced into $S$. cerevisiae in order to make yeast with an improved xylose-fermenting ability (Kim et al. 2010; Madhavan et al. 2009). Recombinant yeasts are impractical for industrial use since they require special containment to confine the engineered microorganisms. The use of recombinant yeasts also increases the initial investment and maintenance costs. On the other hand, the co-culture 
processes are also said to be effective for fermenting both glucose and xylose. The process involves simultaneously utilizing two different yeasts (e.g., S. cerevisiae and $S$. stipitis) which are cultured and grown together in the same reactor (Fu et al. 2009; Yadav et al. 2011). The main bottleneck in this process so far has been the compatibility of these two strains, as one yeast inhibits the growth of the other (Bader et al. 2010; Cardona \& Sanchez 2007; Chen 2011). Both strategies are being pursued. We therefore consider that a single natural yeast strain is desirable for industrial use.

In addition, fermentation at higher temperatures is desirable for the reduction of cooling costs. This requires the use of yeasts which can produce a good yield of ethanol even at elevated temperatures. In separate hydrolysis and fermentation (SHF), enzymatic hydrolysis and ethanolic fermentation are performed separately. To reduce reactor cooling costs, the temperature difference in the two processes must be reduced. Meanwhile, during simultaneous saccharification and fermentation (SSF), a high temperature is required to accelerate enzymatic hydrolysis (Abdel-Banat et al. 2010; Banat et al. 1998; Fonseca et al. 2008; Rodrussamee et al. 2011). The fermentation reaction temperature is determined by the optimal fermentation temperature of the yeast used in either the SHF or SSF process, with the majority of yeasts growing well in the range of $25^{\circ} \mathrm{C}$ to $30^{\circ} \mathrm{C}$. During industrial bioethanol production, the most widely used yeast is $S$. cerevisiae and its optimal temperature is around $30^{\circ} \mathrm{C}$. Consequently, the operating temperatures of glucose and xylose in ethanol conversion systems are fixed at this temperature range. Several researchers have produced bioethanol at high temperatures using thermotolerant yeast strains (Hong et al. 2007; Nonklang et al. 2008; Rajoka et al. 2005; Sridhar et al. 2002); however, ethanol production from only glucose by thermotolerant strains, which were not capable of xylose fermentation to ethanol, have been reported. Considering that xylose is an important sugar in the lignocellulosic biomass (e.g., the xylan content of rice straw can be as high as $20 \%$ (Roberto et al. 2003)), xylose fermentability would clearly be desirable; to date thermotolerant yeasts have not been used in commercial bioethanol plants. Ethanol production from xylose at elevated temperatures however, as detailed by Banat and Marchant (Banat \& Marchant 1995) and by Ishchuk et al. (Ishchuk et al. 2008), resulted in fairly low ethanol productivity. Generally, an increase in temperature leads to a decrease in the rate, yield and/or efficiency of xylose fermentation (Rodrussamee et al. 2011). This suggests it is difficult to identify yeasts suitable for high-yield bioethanol production, which have xylose-fermenting ability and thermotolerance.

In this study, we screened natural yeasts to identify those which can efficiently produce ethanol from xylose and glucose at elevated temperatures. We also examined the ethanol productivity of the selected yeast strain by SSF using rice straw as the feedstock.

\section{Materials and methods}

\section{Isolation of xylose assimilation yeast strains}

Yeast strains were isolated from different natural sources, including flowers, fruits, wood, and soil, obtained from the Kyoto area in Japan (approximately 100 samples in total). The samples were collected in sterilized polypropylene bottles of $15 \mathrm{~mL}$ capacity (Becton Dickinson, Franklin Lakes, NJ, USA) and suspended in $10 \mathrm{~mL}$ of SX liquid medium (3\% xylose and $0.67 \%$ YNB without amino acid; Difco, Detroit, MI, USA) containing chloramphenicol at a concentration of $100 \mu \mathrm{g} /$ $\mathrm{mL}$. The samples were cultivated for 4 days at $30^{\circ} \mathrm{C}$ in static culture with the lids slightly opened. Aliquots (200 $\mu \mathrm{L}$ ) of the culture supernatants were spread onto SX agar medium and incubated aerobically at $30^{\circ} \mathrm{C}$ for 3 days. Yeasts were purified using single-colony isolation. The yeast strains were routinely maintained on YPD agar plates ( $2 \%$ glucose, $2 \%$ peptone [Difco], $1 \%$ yeast extract [Difco] and $1.5 \%$ agar) and grown at $30^{\circ} \mathrm{C}$. YPX medium (4\% xylose, $2 \%$ peptone [Difco] and $1 \%$ yeast extract [Difco]) was used for the screening of xylosefermenting yeast.

\section{Selection of xylose-fermenting yeast with thermotolerance}

Prior to the fermentation experiments, strain ATY839 was inoculated into $3 \mathrm{~mL}$ of YPD medium in test tubes and incubated overnight at $30^{\circ} \mathrm{C}$ with reciprocal shaking at $150 \mathrm{opm}$ (preculture). The preculture was suspended to $25 \mathrm{~mL}$ of synthetic glucose (SG) medium (2\% glucose and $0.67 \%$ YNB without amino acid) or synthetic xylose (SX) medium (2\% xylose and $0.67 \%$ YNB without amino acid) in a $50 \mathrm{~mL}$ Erlenmeyer flask to a cell optical density of 0.1 at $600 \mathrm{~nm}\left(\mathrm{OD}_{600}\right)$ and then cultured at $35^{\circ} \mathrm{C}$, $37^{\circ} \mathrm{C}, 38^{\circ} \mathrm{C}$, or $39^{\circ} \mathrm{C}$ for $48 \mathrm{~h}$ at $120 \mathrm{rpm}$. Sugars and ethanol concentrations of the culture supernatants were determined by following the procedures detailed below. Cell growth was determined at $\mathrm{OD}_{600}$ using a spectrophotometer. All experiments were performed in triplicate.

\section{Determination of sugar and ethanol}

Sugars and ethanol concentrations were determined using a HPLC (Shimadzu, Kyoto, Japan) equipped with an Aminex Fermentation Monitoring Column (Bio-Rad Laboratories, Hercules, CA, USA) and Micro-Guard Cation $\mathrm{H}$ Refill Cartridges with a Standard Cartridge Holder (Bio-Rad Laboratories). Sugars and ethanol were detected using an RID 10A refractive index detector (Shimadzu). The column was kept at $60^{\circ} \mathrm{C}$ using a CTO 
20A column oven (Shimadzu). A sulfuric acid solution (5 mM) was used as the mobile phase at a constant flow rate of $0.6 \mathrm{~mL} / \mathrm{min}$. Portions $(10 \mu \mathrm{L})$ were injected into the HPLC system with a SIL-20A autosampler (Shimadzu), and each run was stopped 14 min after the injection. A Shodex Sugar Column SC1011 (Showa Denko, Tokyo, Japan) was used to measure the glucose and xylose concentrations in SSF hydrolysates: water was used as the mobile phase at a flow rate of $0.6 \mathrm{~mL} / \mathrm{min}$ and at $70^{\circ} \mathrm{C}$. The concentrations of the sugars and ethanol were determined using a standard curve generated by a series of external standards.

\section{Taxonomic identification of the selected yeast strain}

The selected yeast strain was taxonomically identified by 26S rDNA sequencing and the assimilation ability of sugars. The partial $26 \mathrm{~S}$ rDNA of the strain was amplified by PCR and directly sequenced based on a previous method (Kurtzman \& Robnett 1998). The homology of the sequence was determined using the BLAST system of the DNA Data Bank of Japan (DDBJ). The sugar assimilation abilities were evaluated with an API 20C AUX system (BioMerieux, Tokyo, Japan) according to the manufacturer's instructions.

\section{Pretreatment of rice straw}

The rice straw was pretreated with calcium hydroxide according to the alkali treatment method in $\mathrm{CaCCO}$ (calcium capturing by carbonation) process (Park et al. 2010) with some modification. The rice straw employed in this study (cv. Koshihikari) was passed through a high-speed milling machine (PM-2005, Osaka Chemical, Osaka, Japan) and filtered through a $500 \mu \mathrm{m}$ mesh sieve. The milled rice straw (5 g) was added to a $200 \mathrm{~mL}$ Erlenmeyer flask (with a silicone plug) and mixed with calcium hydroxide ( $1 \mathrm{~g}$ ) and water (45 g); the flask was then heated to $120^{\circ} \mathrm{C}$ for $1 \mathrm{~h}$. After cooling to room temperature, the reaction mixture was neutralized by phosphoric acid to a $\mathrm{pH}$ of approximately 6.0, and then $50 \%(\mathrm{w} / \mathrm{v})$ ammonium sulfate solution was added as the nitrogen source (1\% of the final concentration).

\section{SSF of rice straw}

The alkali-treated rice straw was partially hydrolyzed for $2 \mathrm{~h}$ at $50^{\circ} \mathrm{C}$, prior to yeast inoculation, to decrease the viscosity of the suspension and to improve the reproducibility of the results. For the saccharification of rice straw, a combination of cellulase (Celluclast $1.5 \mathrm{~L}$ ), $\beta$-glucosidase (Novozyme 188), and enzyme complex (Ultraflo L) was used for enzymatic saccharification. All enzymes were obtained from Novozymes Japan (Chiba, Japan). The enzyme activity of Celluclast $1.5 \mathrm{~L}$ was $80 \mathrm{FPU} / \mathrm{mL} ; \beta$-glucosidase with an enzyme activity of $322 \mathrm{CBU} / \mathrm{mL}$ was used to hydrolyze cellobiose.
Ultraflo L contained cellulase, xylanase, pentosanase, and arabanase, with an activity of $45 \mathrm{FBG} / \mathrm{g}$. To evaluate the SSF performance of the selected strain, $S$. cerevisiae NBRC 0224, S. stipitis NBRC 10063, and C. shehatae ATCC 22984 were used as control strains. Subsequent to a $2 \mathrm{~h}$ partial hydrolysis, the rice straw was cooled as quickly as possible by immersion in cold water. Cells were cultured and pelleted using centrifugation. The flask was then aseptically inoculated with $2.3 \mathrm{~g}$ (dry cell weight) of yeast cells, corresponding to an $\mathrm{OD}_{600}$ of 20 , and incubated at $37^{\circ} \mathrm{C}$ for $72 \mathrm{~h}$ in a rotary shaker (150 rpm). The SSF were carried out in the same flask as the pretreatment. All experiments were performed in triplicate. The amount of glucose and xylose released from the rice straw were determined to be $33.1 \mathrm{~g} / \mathrm{L}$ and $12.8 \mathrm{~g} / \mathrm{L}$, respectively, following incubation without yeasts at $50^{\circ} \mathrm{C}$ for $24 \mathrm{~h}$. The ethanol yield was calculated as a percentage of a maximum theoretical ethanol yield of $0.51 \mathrm{~g}$ ethanol per gram of glucose or xylose.

\section{Results and discussion}

\section{Screening of xylose-fermenting yeast}

We obtained 72 yeast strains able to ferment xylose from the approximate 100 natural samples collected. The ethanol production ability of each isolated strain was determined using a rich medium with YPX medium containing 4\% xylose. Among the isolated strains, 16 strains produced a significant amount of ethanol from xylose. To examine the fermentability of xylose, the time courses of ethanol concentration and xylose consumption from YPX medium at different temperatures were monitored by HPLC. We observed that one yeast strain, strain ATY839 (which was isolated from soil in Kyoto University) exhibited high xylose fermentability (data not shown).

\section{Temperature characterization of growth and ethanol production in strain ATY839}

To investigate the growth and ethanol production of strain ATY839 at different temperatures, glucose or xylose were fermented at $35,36,38$, and $39^{\circ} \mathrm{C}$. The time course analyses of cell growth in SG and SX media are shown in Figure 1a and Figure 1b, respectively. Strain ATY 839 was able to grow even at $39^{\circ} \mathrm{C}$ in any of the carbon sources tested.

To determine the effects of temperature on fermentation by strain ATY839, the changes in glucose and ethanol concentrations with SG media were measured (Figure 2). As the temperature increased, glucose consumption decreased (Figure 2a). Strain ATY839 completely consumed glucose below $37^{\circ} \mathrm{C}$. However, glucose consumption was not complete, above $38^{\circ} \mathrm{C}$, until $48 \mathrm{~h}$. At $37^{\circ} \mathrm{C}$, strain ATY839 produced approximately the same amount of ethanol as at $35^{\circ} \mathrm{C}$ (Figure 2b). For these 


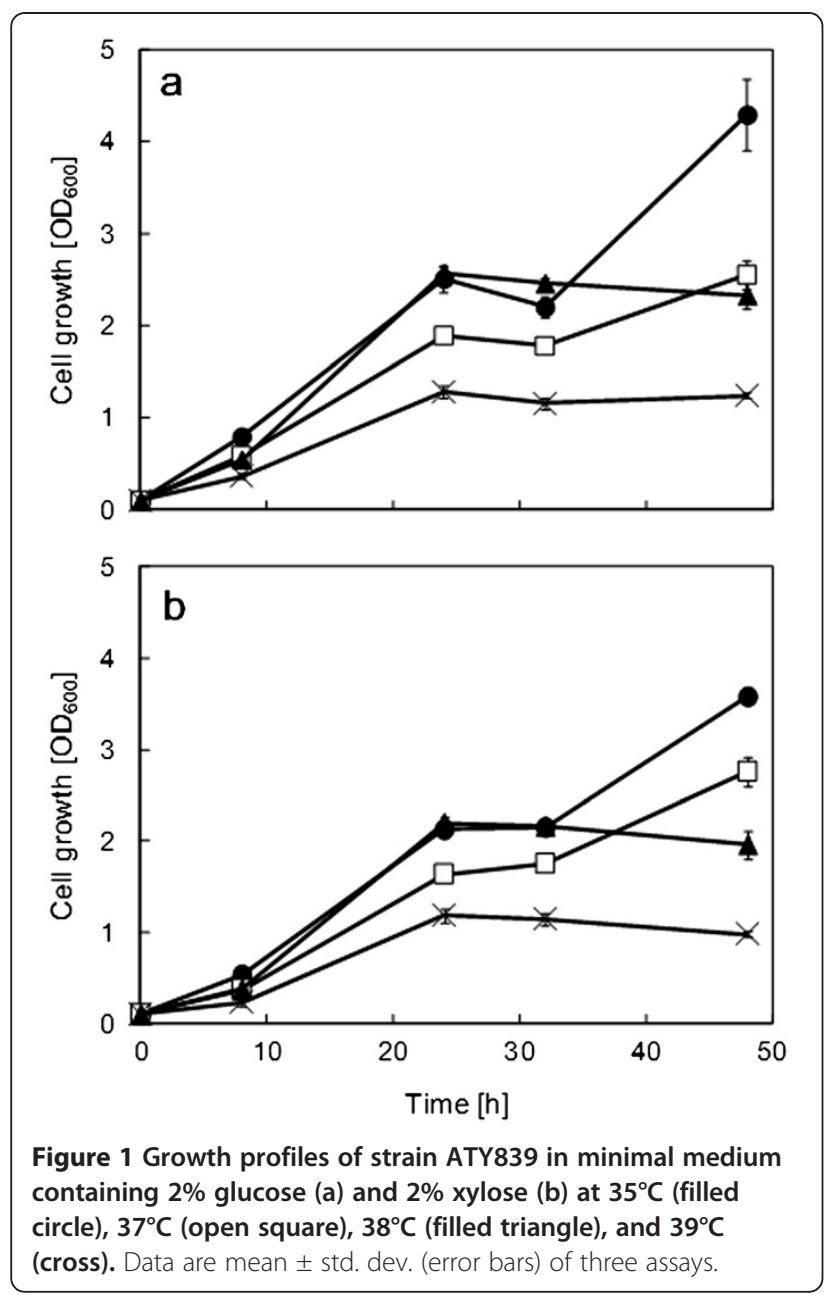

reasons, it is possible to say that strain ATY839 is able to maintain good glucose fermentability up to $37^{\circ} \mathrm{C}$. The results of xylose and ethanol concentrations with SX media are shown in Figure 3. Sugar utilization patterns are greatly influenced by the type of sugar used as the carbon source. It is known that xylose utilization is slower compared with glucose. Moreover, the ethanol production rate of xylose-fermenting yeasts in a medium containing xylose as the sole carbon source is about half that when in a medium containing glucose as the sole carbon source (Grootjen et al. 1990; Ligthelm et al. 1988). Therefore, xylose was not completely consumed at every temperature within $48 \mathrm{~h}$. In the case of glucose fermentation, the maximum ethanol concentration at $35^{\circ} \mathrm{C}$ and $37^{\circ} \mathrm{C}$ were approximately same (Figure $2 \mathrm{~b}$ ); on the other hand, in the case of xylose fermentation, a high ethanol production level was maintained at $37^{\circ} \mathrm{C}$, although the ethanol production level was a little decreased, compared with ethanol production at $35^{\circ} \mathrm{C}$ (approx. 80\%) (Figure 3b). The data suggests that the maximum ethanol production temperature varies with
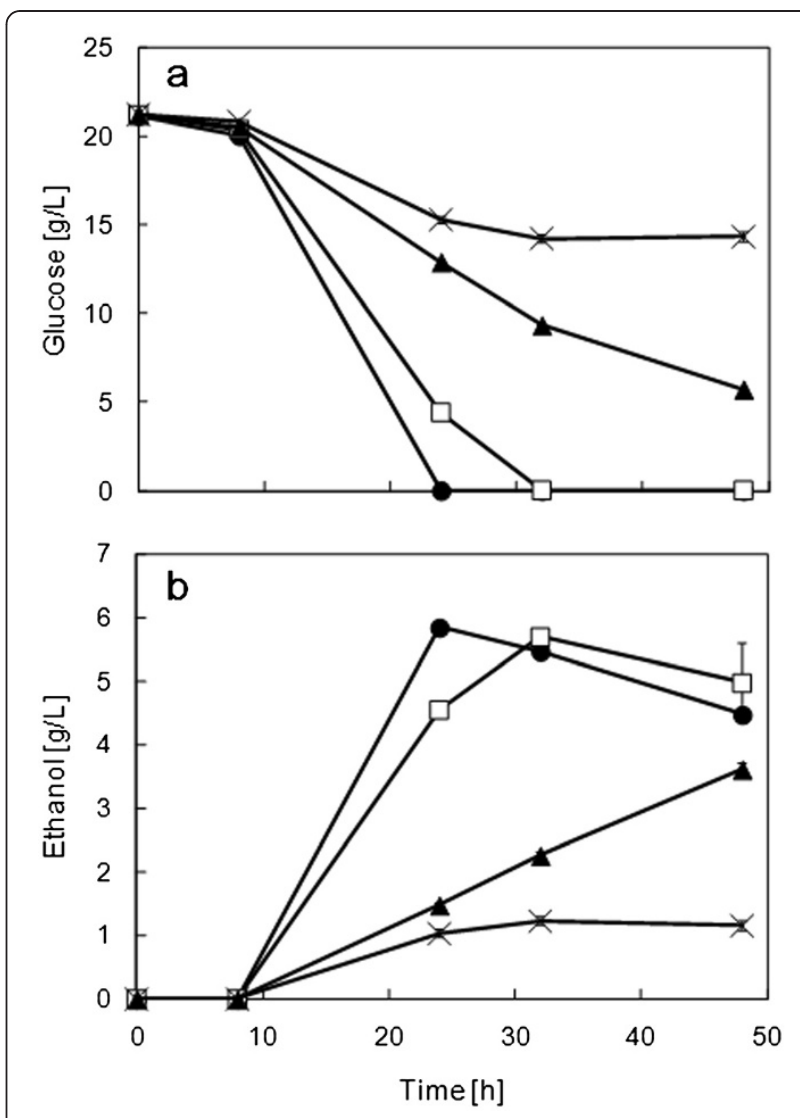

Figure 2 Time course analyses of glucose consumption (a), and ethanol formation (b) in SG media using strain ATY839 at $35^{\circ} \mathrm{C}$ (filled circle), $37^{\circ} \mathrm{C}$ (open square), $38^{\circ} \mathrm{C}$ (filled triangle), and $39^{\circ} \mathrm{C}$ (cross). Data are mean \pm std. dev. (error bars) of three assays.

the carbon source; there was a threshold of xylose-toethanol conversion ability between $37^{\circ} \mathrm{C}$ to $38^{\circ} \mathrm{C}$, as found with glucose. For these reasons, it can be stated that $37^{\circ} \mathrm{C}$ is the upper limit of practical fermentation of strain ATY839; however, it can grow at $39^{\circ} \mathrm{C}$ (Figure 1). It is possible to say that strain ATY839 has a high potential for ethanol production from glucose and xylose.

It is speculated that strain ATY839 possesses defense mechanisms against and/or adaptation to higher temperatures, such as the adjustment of membrane composition and accumulation of heat shock proteins and/or trehalose (Devirgilio et al. 1994; Zhao \& Bai 2009). As the xylose-fermenting ability is weakened at elevated temperature, suitable conditions such as $\mathrm{pH}$, aeration, cell density, and nutrient concentrations will need to be determined in detail.

\section{Taxonomic identification of strain ATY839}

For the phylogenetic analysis of strain ATY839, 26S rDNA sequencing was performed and the assimilation potential of various sugars was tested (Table 1). The 

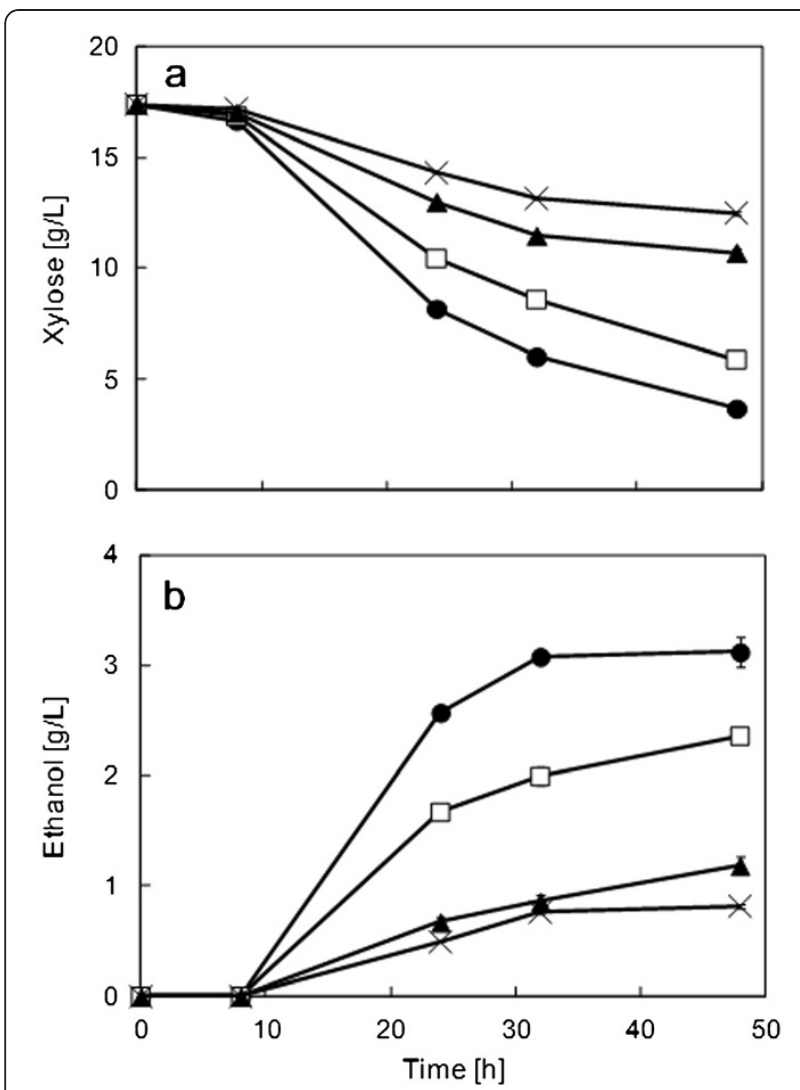

Figure 3 Time course analyses of xylose consumption (a), and ethanol formation (b) in SX media using strain ATY839 at $35^{\circ} \mathrm{C}$ (filled circle), $37^{\circ} \mathrm{C}$ (open square), $38^{\circ} \mathrm{C}$ (filled triangle), and $39^{\circ} \mathrm{C}$ (cross). Data are mean \pm std. dev. (error bars) of three assays.

sequence of 26S rDNA of strain ATY839 showed 99.5\% identity to that of Candida shehatae CBS 4704. The sequence has been recorded in the DDBJ database under the accession number AF178049. The sugar assimilation test of strain ATY839 gave results similar to those for C. shehatae CBS 5813 (Kurtzman et al. 2010). For these reasons, we regard strain ATY839 as belonging

Table 1 Assimilation patterns of various sugars of strain ATY839

\begin{tabular}{lllr}
\hline D-Glucose & + & D-Sorbitol & + \\
Glycerol & + & a-Methyl-D-glucoside & + \\
2-Keto-D-gluconic acid & + & N-Acethyl-glucosamine & + \\
hemicalcium salt & & D-Cellobiose & + \\
L-Arabinose & - & D-Lactose & W \\
D-Xylose & + & D-Maltose & + \\
Adonitol & + & D-Saccharose & + \\
Xylitol & W & D-Trehalose & + \\
D-Galactose & + & D-Melezitose & + \\
Inositol & W & D-Raffinose & - \\
\hline
\end{tabular}

+: positive, -: negative, w: weak.
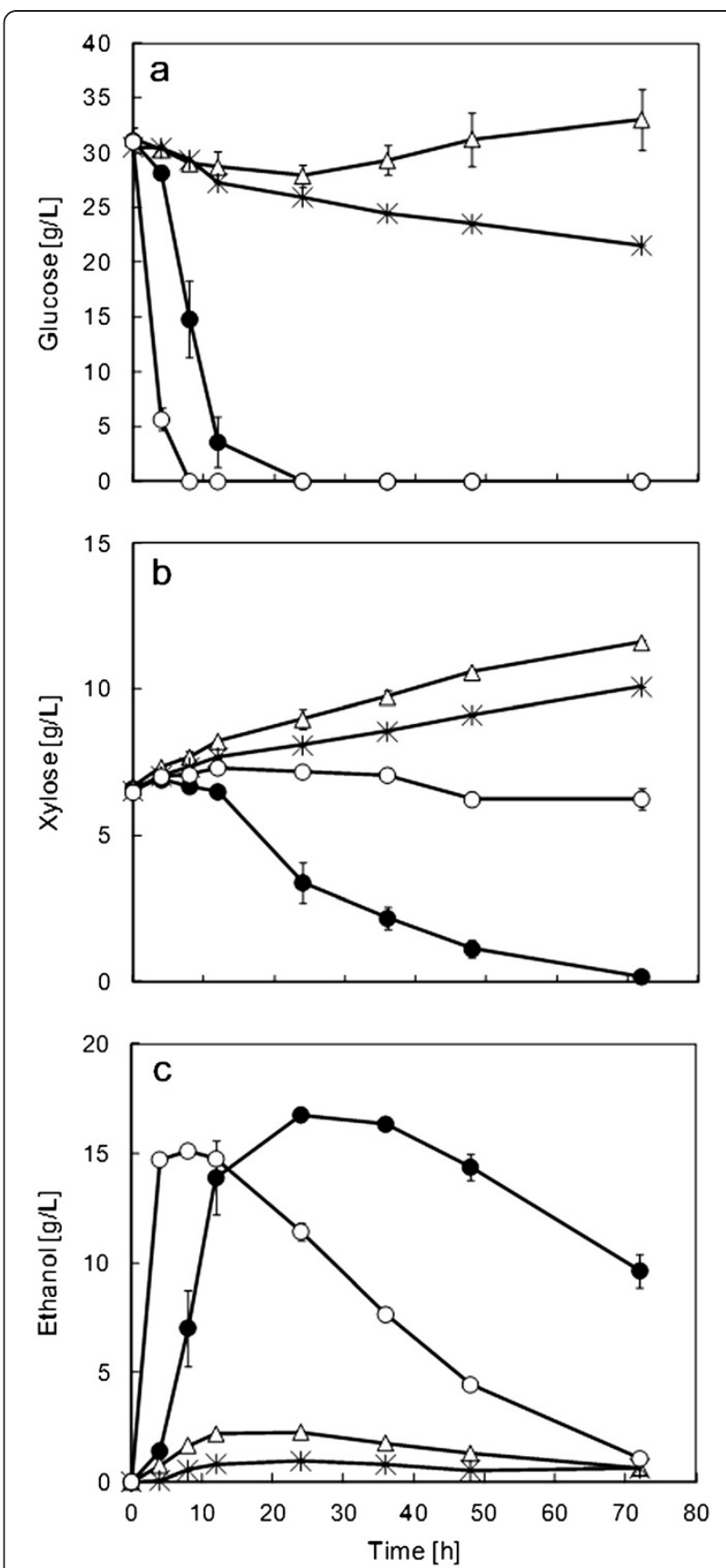

Figure 4 Time course analyses of glucose consumption (a), xylose consumption (b), and ethanol formation (c) in the SSF process of rice straw using S. cerevisiae NBRC 0224 (open circle), S. stipitis NBRC 10063 (asterisk), C. shehatae ATCC 22984 (open triangle), and strain ATY839 (filled circle) at $37^{\circ} \mathrm{C}$. Data are mean \pm std. dev. (error bars) of three assays.

to $C$. shehatae and it is one of the most tolerant strains to high temperature within $C$. shehatae.

\section{SSF using alkali-treated rice straw at $37^{\circ} \mathrm{C}$}

Strain ATY839 showed superior fermentative performance at elevated temperature, as can be seen in Figures 1, 
2 and 3. Strain ATY839 was found to be more suitable for lignocellulosic biomass fermentation than S. cerevisiae, as xylose is the major constituent; accordingly, we demonstrated this suitability by performing SSF using rice straw as a substrate at $37^{\circ} \mathrm{C}$. Data on the ethanol production and sugar consumption in SSF of alkalipretreated rice straw are shown in Figure 4. Both S. stipitis NBRC 10063 and C. shehatae ATCC 22984 produced hardly any ethanol. In contrast, S. cerevisiae NBRC 0224 and strain ATY839 produced substantial amounts of ethanol from glucose and xylose derived from rice straw. This result was in agreement with those obtained in the experiments using minimal medium. The fermentation by S. cerevisiae NBRC 0224 was almost complete after 8 $\mathrm{h}$, with an ethanol concentration of $15.1 \mathrm{~g} / \mathrm{L}$. The maximum theoretical ethanol yield of $S$. cerevisiae NBRC 0224 at $8 \mathrm{~h}$ was $64.5 \%$. After $8 \mathrm{~h}$ fermentation, the ethanol concentration decreased which may be attributable to the assimilation of yeast cells. During SSF, using strain ATY839, the ethanol concentration reached $16.8 \mathrm{~g} / \mathrm{L}$ (71.6\% of the maximum theoretical ethanol yield) at 24 $\mathrm{h}$; after $24 \mathrm{~h}$, the ethanol concentration in the ATY839 strain cultures was slightly decreased despite the presence of xylose. The reduction of ethanol in strain ATY839 cultures may be attributable to excess aeration. It has been reported that the aeration rate was one of the most important parameters in attaining maximum ethanol concentration with xylose-fermenting yeasts (Sanchez et al. 1997). This phenomenon is possibly due to the change of metabolism, but metabolic rationale is another factor to be considered and will be the focus of our future studies. Strain ATY839 completely consumed xylose within $72 \mathrm{~h}$ under high-temperature conditions. Although it is difficult to control the dissolved oxygen level in the SSF of rice straw, the ethanol-producing ability should be assessed in our strains under optimum conditions in future work. However, this study has confirmed that strain ATY839 performed better than the other xylose-fermenting yeasts tested.

Although S. stipitis is a yeast exhibiting excellent xylose-fermenting ability, it did not perform well under high-temperature conditions; in contrast to strain ATY839 which produced ethanol under such conditions. Among the C. shehatae strains, ATCC 22984 is a wellcharacterized strain; Li et al. (Li et al. 2012) isolated a high-ethanol-yield mutant from $C$. shehatae ATCC 22984 by UV irradiation and cultivation with a medium containing antimycin $\mathrm{A}$, suggesting that the introduction of a mutation may be effective for improving $C$. shehatae. It is possible that $C$. shehatae mutants derived from strain ATY839 by a method such as that described in $\mathrm{Li}$ et al. (Li et al. 2012) will show more suitable characteristics for bioethanol production from a lignocellulosic biomass.
In conclusion, this study provides the first report of the isolation of a natural yeast strain, designated ATY839, which converts both glucose and xylose to ethanol with high efficiency at an elevated temperature. The fermentation experiments in SX medium revealed that strain ATY839 efficiently produced ethanol from xylose (Figure 3). Excellent fermentability was observed with xylose utilization even at $37^{\circ} \mathrm{C}$. To our knowledge, strain ATY839 is the most tolerant strain to heat stress among the $C$. shehatae strains. Additionally, we performed SSF with strain ATY839 and control strains, and evaluated each strain's ability to utilize rice straw as the feedstock for bioethanol production. The results suggest that strain ATY839 is more suitable than S. cerevisiae or S. stipitis for producing ethanol from a lignocellulosic biomass. However, further investigations are required to improve the ability of strain ATY839 to produce ethanol from sugars derived from a lignocellulosic biomass. It may also be useful as a genetic resource for engineering xylose metabolism in S. cerevisiae in order to improve its ability to convert xylose to ethanol.

\section{Competing interests}

The authors declare that they have no competing interests.

\section{Authors' contributions}

AT carried out the screening and identification studies, analyzed the data and drafted the manuscript. TN designed methods and experiments, interpreted the data and revised the manuscript. TN and IW carried out the fermentation studies. JO assisted with data analysis. JS conceived the idea, supervised the study and revised the manuscript. All authors read and approved the final manuscript.

\section{Acknowledgments}

This work was supported financially by the Institute for Fermentation, Osaka (IFO), and by grants from the Ministry of Agriculture, Forestry, and Fisheries of Japan (Rural Biomass Research Project, BEC-BC050, BEC-BC051). We thank E. Nakao for the constructive comments and warm encouragement.

\section{Author details}

${ }^{1}$ Research Division of Microbial Sciences, Kyoto University, Kitashirakawa Oiwake-Cho, Sakyo-ku, Kyoto 606-8502, Japan. ${ }^{2}$ National Food Research Institute, National Agriculture and Food Research Organization (NARO), 2-1-12 Kannondai, Tsukuba, Ibaraki 305-8642, Japan. ${ }^{3}$ Division of Applied Life Sciences, Graduate School of Agriculture, Kyoto University, Kitashirakawa Oiwake-Cho, Kyoto, Sakyo-ku 606-8502, Japan.

Received: 12 September 2012 Accepted: 2 October 2012

Published: 4 October 2012

\section{References}

Abdel-Banat BMA, Hoshida H, Ano A, Nonklang S, Akada R (2010) Hightemperature fermentation: how can processes for ethanol production at high temperatures become superior to the traditional process using mesophilic yeast? Appl Microbiol Biotechnol 85:861-867

Bader J, Mast-Gerlach E, Popovic MK, Bajpai R, Stahl U (2010) Relevance of microbial coculture fermentations in biotechnology. J Appl Microbiol 109:371-387

Balat M (2011) Production of bioethanol from lignocellulosic materials via the biochemical pathway: A review. Energ Convers Manage 52:858-875

Banat IM, Marchant R (1995) Characterization and potential industrial applications of 5 novel, thermotolerant, fermentative, yeast strains. World J Microbiol Biotechnol 11:304-306 
Banat IM, Nigam P, Singh D, Marchant R, McHale AP (1998) Ethanol production at elevated temperatures and alcohol concentrations: Part I - Yeasts in general. World J Microbiol Biotechnol 14:809-821

Binod P, Sindhu R, Singhania RR, Vikram S, Devi L, Nagalakshmi S, Kurien N, Sukumaran RK, Pandey A (2010) Bioethanol production from rice straw: An overview. Bioresour Technol 101:4767-4774

Cardona CA, Sanchez OJ (2007) Fuel ethanol production: Process design trends and integration opportunities. Bioresour Technol 98:2415-2457

Chen $Y$ (2011) Development and application of co-culture for ethanol production by co-fermentation of glucose and xylose: a systematic review. J Ind Microbiol Biotechnol 38:581-597

Devirgilio C, Hottiger T, Dominguez J, Boller T, Wiemken A (1994) The role of trehalose synthesis for the acquisition of thermotolerance in yeast.1. Genetic evidence-that trehalose is a thermoprotectant. Eur J Biochem 219:179-186

Fonseca GG, Heinzle E, Wittmann C, Gombert AK (2008) The yeast Kluyveromyces marxianus and its biotechnological potential. Appl Microbiol Biotechnol 79:339-354

Fu N, Peiris P, Markham J, Bavor J (2009) A novel co-culture process with Zymomonas mobilis and Pichia stipitis for efficient ethanol production on glucose/xylose mixtures. Enzyme Microb Technol 45:210-217

Grootjen DRJ, Vanderlans R, Luyben K (1990) Effects of the aeration rate on the fermentation of glucose and xylose by Pichia-stipitis CBS-5773. Enzyme Microb Technol 12(1):20-23

Hong J, Wang Y, Kumagai H, Tamaki H (2007) Construction of thermotolerant yeast expressing thermostable cellulase genes. J Biotechnol 130:114-123

Hou X (2012) Anaerobic xylose fermentation by Spathaspora passalidarum. Appl Microbiol Biotechnol 94(1):205-214

Ishchuk OP, Voronovsky AY, Stasyk OV, Gayda GZ, Gonchar MV, Abbas CA, Sibirny AA (2008) Overexpression of pyruvate decarboxylase in the yeast Hansenula polymorpha results in increased ethanol yield in high-temperature fermentation of xylose. FEMS Yeast Res 8:1164-1174

Jeffries TW, Jin YS (2004) Metabolic engineering for improved fermentation of pentoses by yeasts. Appl Microbiol Biotechnol 63:495-509

Jeffries TW, Grigoriev IV, Grimwood J, Laplaza JM, Aerts A, Salamov A, Schmutz J, Lindquist E, Dehal P, Shapiro H, Jin Y-S, Passoth V, Richardson PM (2007) Genome sequence of the lignocellulose-bioconverting and xylosefermenting yeast Pichia stipitis. Nat Biotechnol 25(3):319-326

Kim S, Dale BE (2004) Global potential bioethanol production from wasted crops and crop residues. Biomass Bioenergy 26:361-375

Kim J-H, Block DE, Mills DA (2010) Simultaneous consumption of pentose and hexose sugars: an optimal microbial phenotype for efficient fermentation of lignocellulosic biomass. Appl Microbiol Biotechnol 88:1077-1085

Kuhad RC, Gupta R, Khasa YP, Singh A, Zhang YHP (2011) Bioethanol production from pentose sugars: Current status and future prospects. Renew Sust Energ Rev 15:4950-4962

Kurtzman CP, Robnett CJ (1998) Identification and phylogeny of ascomycetous yeasts from analysis of nuclear large subunit (26S) ribosomal DNA partial sequences. Antonie Van Leeuwenhoek 73:331-371

Kurtzman CP, Fell JW, Boekhout T (2010) The yeasts: a taxonomic study 5th edn Elsevier Science, The Netherlands, pp 1220-1221

Li Y, Park J-y, Shiroma R, Ike M, Tokuyasu K (2012) Improved ethanol and reduced xylitol production from glucose and xylose mixtures by the mutant strain of Candida shehatae ATCC 22984. Appl Biochem Biotechnol 166:1781-1790

Ligthelm ME, Prior BA, du Preez JC (1988) The oxygen requirements of yeasts for the fermentation of D-xylose and D-glucose to ethanol. Appl Biochem Biotechnol 28:63-68

Madhavan A, Tamalampudi S, Srivastava A, Fukuda H, Bisaria VS, Kondo A (2009) Alcoholic fermentation of xylose and mixed sugars using recombinant Saccharomyces cerevisiae engineered for xylose utilization. Appl Microbiol Biotechnol 82:1037-1047

Nonklang S, Abdel-Banat BMA, Cha-aim K, Moonjai N, Hoshida H, Limtong S, Yamada M, Akada R (2008) High-temperature ethanol fermentation and transformation with linear DNA in the thermotolerant yeast Kluyveromyces marxianus DMKU3-1042. Appl Environ Microbiol 74:7514-7521

Park J-y, Shiroma R, Al-Haq MI, Zhang Y, Ike M, Arai-Sanoh Y, Ida A, Kondo M, Tokuyasu K (2010) A novel lime pretreatment for subsequent bioethanol production from rice straw - Calcium capturing by carbonation ( $\mathrm{CaCCO})$ process. Bioresour Technol 101:6805-6811

Prior BA, Kilian SG, du Preez JC (1989) Fermentation of D-xylose by the yeasts Candida-shehatae and Pichia-stipitis - Prospects and problems. Process Biochem 24(1):21-32
Rajoka MI, Ferhan M, Khalid AM (2005) Kinetics and thermodynamics of ethanol production by a thermotolerant mutant of Saccharomyces cerevisiae in a microprocessor-controlled bioreactor. Lett Appl Microbiol 40:316-321

Roberto IC, Mussatto SI, Rodrigues R (2003) Dilute-acid hydrolysis for optimization of xylose recovery from rice straw in a semi-pilot reactor. Ind Crops Prod $17: 171-176$

Rodrussamee N, Lertwattanasakul N, Hirata K, Suprayogi LS, Kosaka T, Yamada M (2011) Growth and ethanol fermentation ability on hexose and pentose sugars and glucose effect under various conditions in thermotolerant yeast Kluyveromyces marxianus. Appl Microbiol Biotechnol 90:1573-1586

Sanchez OJ, Cardona CA (2008) Trends in biotechnological production of fuel ethanol from different feedstocks. Bioresour Technol 99:5270-5295

Sanchez S, Bravo V, Castro E, Moya AJ, Camacho F (1997) The influence of pH and aeration rate on the fermentation of D-xylose by Candida shehatae. Enzyme Microb Technol 21:355-360

Sarkar N, Ghosh SK, Bannerjee S, Aikat K (2012) Bioethanol production from agricultural wastes: An overview. Renew Energ 37:19-27

Sridhar M, Sree NK, Rao LV (2002) Effect of UV radiation on thermotolerance, ethanol tolerance and osmotolerance of Saccharomyces cerevisiae VS 1 and $V_{S_{3}}$ strains. Bioresour Technol 83:199-202

Yadav KS, Naseeruddin S, Prashanthi GS, Sateesh L, Rao LV (2011) Bioethanol fermentation of concentrated rice straw hydrolysate using co-culture of Saccharomyces cerevisiae and Pichia stipitis. Bioresour Technol 102:6473-6478

Zhao XQ, Bai FW (2009) Mechanisms of yeast stress tolerance and its manipulation for efficient fuel ethanol production. J Biotechnol 144:23-30

doi:10.1186/2193-1801-1-27

Cite this article as: Tanimura et al.: Isolation of a novel strain of Candida shehatae for ethanol production at elevated temperature. SpringerPlus 2012 1:27.

\section{Submit your manuscript to a SpringerOpen ${ }^{\circ}$ journal and benefit from:}

- Convenient online submission

- Rigorous peer review

- Immediate publication on acceptance

- Open access: articles freely available online

- High visibility within the field

- Retaining the copyright to your article

Submit your next manuscript at springeropen.com 